\title{
Early Detection of Epiphytic Anthracnose Inoculum on Phyllosphere of Diospyros kaki var. domestica
}

\author{
Jung Han Lee, Ki Soo Han, Sun Cheol Lee, Chang Ki Shim, Dong Won Bae', Dong Kil Kim and \\ Hee Kyu Kim ${ }^{1 *}$ \\ Department of Applied Biology \& Environmental Sciences, Gyeongsang National University, Jinju 660-701, Korea \\ ${ }^{\prime}$ Research Institute of Life Science and ${ }^{2}$ Central Laboratory, Gyeongsang National University, Jinju 660-701, Korea
}

(Received on June 30, 2004; Accepted on November 14, 2004)

We developed a polyclonal antibody (PAb) basedELISA system to accurately and rapidly monitor inocula on plant surface before onset of anthracnose. Titer of mouse antisera against conidia of Colletotrichum gloeosporioides was determined by using indirect ELISA. It was high enough to be detectable up to $\times 12,800$ dilutions. Absorbance readings exceeded 0.5 even at a $10^{-5}$ dilution. Sensitivity of PAb was precise enough to detect spore concentration as low as $\mathbf{5 0}$ conidia/well by indirect ELISA. PAb1 and PAb2 proved to be very sensitive and highly specific to the target pathogen, $C$. gloeosporioides, apparently discriminating other unrelated pathogens, or epiphytes. Absorbance values for original isolate exceeded 1.0 , but no reaction was detected with other isolates, except three other anthracnose fungi: $C$. gloeosporioides (pepper strain), Glomerella cingulata (apple strain) and $C$. lagenarium. Our data suggest that PAb1 and PAb2 bind with the protein epitope that partially contains residues of amino acid, arginine, and lysine. This kit fulfills the requirements for detecting inoculums before infection and during onset of anthracnose on sweet persimmon.

Keywords : Diospyros kaki, anthracnose, indirect ELISA

Anthracnose is one of the most serious diseases of sweet persimmon. The pathogen-causing disease has been known as Gloeosporium kaki, and lately renamed as Colletotrichum gloeosporioides (Kobayashi, T. and Katumoto, K., 1992). Its cultural characteristics have been described by Kwon et al. (2000). Water sprouts on improperly pruned trees in poorly managed orchards are major targets for infection and also sources of inoculum. Conidia are splash-dispersed to twigs and fruits, where they germinate to produce appressoria. Early infection on fruit, predisposed by frequent rainfall in May to June, causes premature preharvest fruit rot, and later, infection causes post-harvest anthracnose.

\footnotetext{
* Corresponding author.

Phone) +82-55-751-5443, FAX) +82-55-752-8204

E-mail) heekkim@nongae.gsnu.ac.kr
}

Detection of specific fungi on phyllosphere, or in plant tissues in the presence of other fungi, is difficult. Classical methods such as isolation on selective media are useful; but many pathogens are often masked by overgrowth of faster growing fungi (Meyer et al., 2000). Therefore, rapid and accurate diagnostic tools are required for their detection and identification.

Clark (1981) emphasized the potential of enzyme-linked immunosorbent assays for detecting and identifying plant pathogen in much lower concentration than that obtained when one is using classical methods. Most assays and experiments have used plant viruses, but the same technique has been attempted to detect bacterial and fungal plant pathogens.

Sundaram et al. (1991) reported that polyclonal $\mathrm{Ab}$ based-indirect ELISA, prepared against purified mycelial proteins from Verticillium dahliae, reacted positively with 11 of 12 isolates from potato, cotton, and soil. However, this negatively reacted with one isolate from tomato, and also with non-target pathogens, Fusarium oxysporum, Colletotrichum lindemuthianum, Rhizoctonia solani, $V$. nigrescens, and $V$. tricorpus. Their antiserum reacted strongly with Verticillium dahliae and intensely with $V$. albo-atrum.

Velicheti et al. (1993), using polyclonal Ab based DASELISA, attempted to develop an assay that would result in early detection of Phomopsis phaseoli and Phomopsis longicolla of soybean. Unfortunately, their assay system yielded cross-reaction with all Phomopsis sp. and Colletotrichum truncatum, although, it discriminated Phytophthora sojae, Rhizopus sp., Rhizoctonia solani, Septoria glycines, and Cercospora kikuchii.

As an alternative, polymerase chain reactions ( $\mathrm{PCR}$ ) have been developed by using a specific primer to pathogens (Singh et al., 2000). The PCR assay proved to be a highly sensitive method for detecting very low titers of pathogens. But enzyme-linked immunosorbent assay (ELISA) is often preferred over PCR because PCR test is costly and timeconsuming for testing large number of samples (Somai et al., 2002). 
ELISA method is simple to operate, specific, and highly sensitive in detecting and identifying the target pathogen.

In this study, we developed a polyclonal antibody basedELISA system for the conidia of sweet persimmon anthracnose pathogen.

\section{Materials and Methods}

Antigen preparation. Anthracnose pathogen was isolated from Diospyros kaki var. domestica Makino in Gyeongnam province. Sample slices were placed on water agar and incubated for 2 days at $27^{\circ} \mathrm{C}$. The typical colonies from the samples were transferred into potato dextrose agar (PDA, Difco) for further studies. Other fungal isolates were used for screening the cross-reactivity of PAb.

Mycelial colony on the PDA plate was cultured at $27^{\circ} \mathrm{C}$ for 7 days under the dark condition, and irradiated under the fluorescent lamp for further 3-4 days at $27^{\circ} \mathrm{C}$. Large quantities of mass-produced conidia on PDA were collected by washing off the colony surface on PDA plate with $2 \mathrm{ml}$ of ultra pure water and filtering these through cheesecloth. The spore suspension was centrifuged for $5 \mathrm{~min}$ at $8,000 \mathrm{rpm}$, and resuspended to about $1 \times 10^{6} \mathrm{cfu} / \mathrm{ml}$ in physiological salt solution $(0.9 \% \mathrm{NaCl})$. The suspension, used as the immunogen, was aliquoted and stored at $-20^{\circ} \mathrm{C}$ until use.

Polyclonal antibody production. In preparation for the first injection, the spore suspension $(300 \mu \mathrm{L})$ was mixed with an equal volume of Freund's Complete Adjuvant (Sigma F-5881) to make emulsion by 3 -WAY STOPCOCK. The antigen-adjuvant mixture $(800 \mu \mathrm{L})$ was injected into the ascites of two female (6-weeksold) BALB/C mice $(200 \mu \mathrm{L} /$ mouse). The first injection was followed by two-booster injection at a three-week interval. For the second injection, the spore suspension was mixed with incomplete adjuvant (Gibco cat. 15720-030). Third injection was done with equal volume mixture of the spore suspension and physiological salt solution $(0.9 \% \mathrm{NaCl})$.

For serum preparation, blood sample was collected in E-tube from mouse tail 2 days after the 3 rd injection, and was exposed to room temperature for $5 \mathrm{~min}$. Anti-serum was prepared by centrifugation at 3,000 rpm for $10 \mathrm{~min}$ and subjected to titration by ELISA.

ELISA Method. Indirect ELISA was performed for screening of antisera. Aliquots of conidia suspension was dissolved in carbonate coating buffer $\left(10^{7}\right.$ spore $\left.\mathrm{ml}^{-1}\right)$, and dispensed in $50 \mu \mathrm{L}$ per well at $4^{\circ} \mathrm{C}$ overnight. Coated wells were washed three times with PBST $\left(0.8 \% \mathrm{NaCl}, 0.02 \% \mathrm{KCl}, 0.115 \% \mathrm{Na}_{2} \mathrm{HPO}_{4}, 0.02 \%\right.$ $\mathrm{KH}_{2} \mathrm{PO}_{4}, 0.05 \%$ Tween $20, \mathrm{pH} 7.4$ ), and uncoated well surfaces were blocked with $1 \%$ skim milk for $30 \mathrm{~min}$ at room temperature. After being washed thrice with PBST, wells were incubated at $37^{\circ} \mathrm{C}$ for $1 \mathrm{~h}$ with $50 \mu \mathrm{L}$ antisera appropriately diluted in $1 \% \mathrm{BSA}$ per well. Wells were again washed three times with PBST, and then incubated at $37^{\circ} \mathrm{C}$ for $1 \mathrm{~h}$ with secondary antibody (Sigma A0412, goat Anti-mouse Polyvalent IgG, IgA, IgM, peroxidase conjugate diluted $1: 10,000$ in $1 \%$ BSA).

A $50 \mu \mathrm{L}$ substrate solution (o-phenylenediamine $4 \mathrm{mg} / 5 \mathrm{ml}$; PCB $0.1 \mathrm{M}$ phosphate-citrate, $10 \mu \mathrm{L} \mathrm{H}_{2} \mathrm{O}_{2}$ ) was administered to each well after the wells went through five times of washing. The reaction was stopped by adding $50 \mu \mathrm{L}$ of $2 \mathrm{~N} \mathrm{H}_{2} \mathrm{SO}_{4}$ for $15 \mathrm{~min}$., followed by OD reading in ELISA reader (BIO-RAD, Model 550 ) at $490 \mathrm{~nm}$.

Titer of antisera was determined by adding $50 \mu \mathrm{L}$ antisera of two-fold dilution from 100 to $3,296,800$ in $1 \%$ BSA after blocking with $1 \%$ skim milk using ELISA system (Fig. 1).

Sensitivity of PAb was also determined; the plates were coated with conidia, serial ten-fold dilutions from $10^{10}$ to $10^{\circ}$ well, and each well received $50 \mu \mathrm{L}$ PAb (1:10,000 dilution, Fig. 2).

Antigen determination. To determine antigen, conidia $v s$. mucous conidia surface washing was coated to plate and subsequently introduced with $\mathrm{PAb} 1$ and $\mathrm{PAb} 2$, then visualized in indirect ELISA.

Specificity test of PAb for Colletotrichum gloeosporioides. Specificity of $\mathrm{Pab}$ for Colletotrichum gloeosporioides against other pathogens was also tested. The ELISA plates prepared with $\mathrm{Pab}$, as mentioned above, were tested for reactivity to isolates of Colletotrichum gloeosporioides, as well as other pathogens in Diospyros kaki var. domestica Makino.

Antigen characterization. The Colletotrichum gloeosporioides antigen was characterized by incubating conidia, immobilized in micro titer wells $(50 \mu \mathrm{L})$, with either pronase, protenase $\mathrm{K}$, and trypsin solution, or with cellulase, lysozyme and pectinase at $37^{\circ} \mathrm{C}$ from 1 to $5 \mathrm{~min}$ at $1 \mathrm{~min}$ intervals. This was to capture any reaction that would occur in the process. Then, the wells were washed three times with PBST, which were blocked with $1 \%$ skim milk. Control wells received only PBST without enzyme but were otherwise treated similarly. The influence of those treatment was monitored by ELISA scheme

\section{Results}

Titer of polyclonal antibody against Colletotrichum gloeosporioides. In producing PAb1 and PAb2 against Colletotrichum gloeosporioides, we used conidia as an immunogen. After being immunized, titer of mouse antisera against Colletotrichum gloeosporioides, determined by

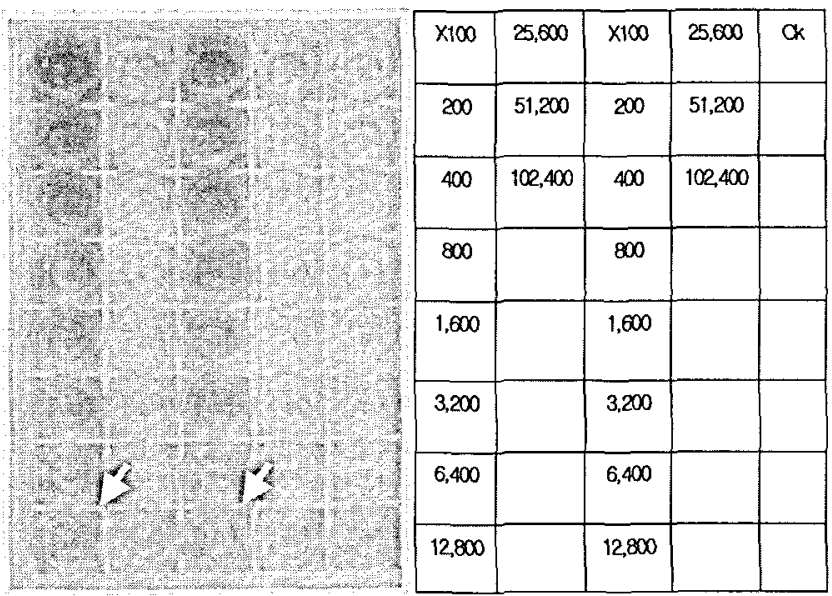

Fig. 1. Titer of polyclonal antibody against Colletotrichum gloeosporioides. CK, negative control. 


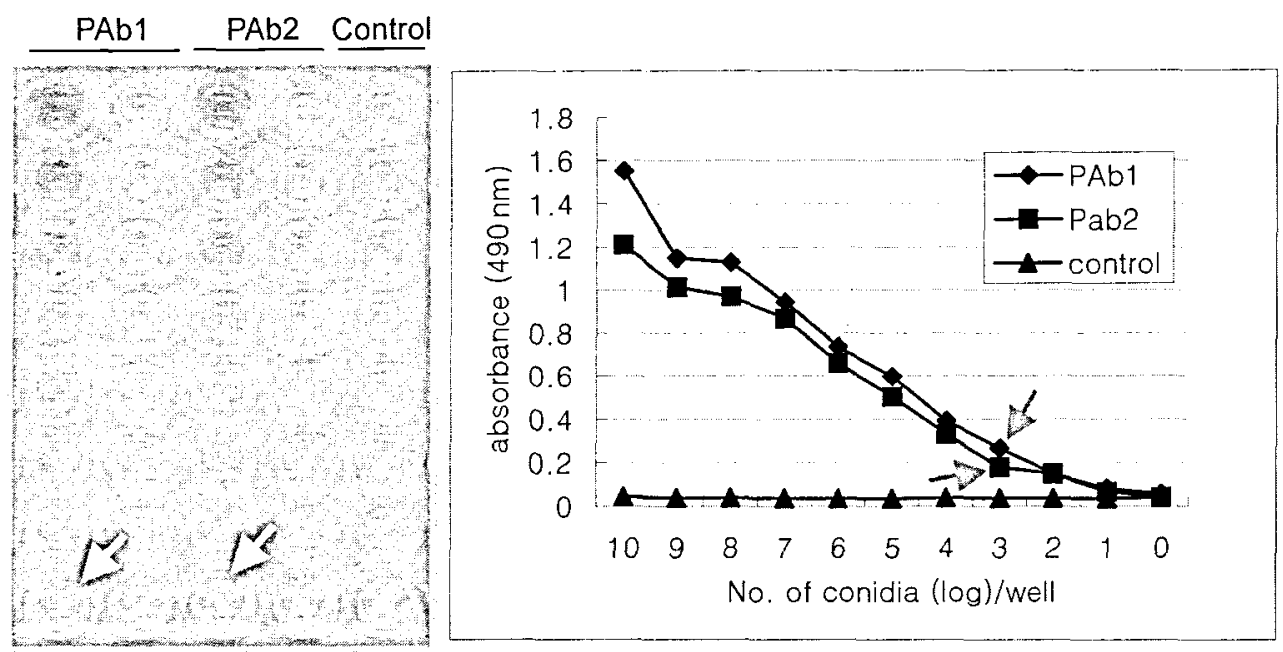

Fig. 2. Sensitivity of PAbs $1 \& 2$ to the threshold conidia concentration of Colletotrichum gloeosporioides by indirect ELISA. Plates were coated with conidia, and antiserum was diluted $1: 1,000(\mathrm{v} / \mathrm{v})$. Arrow indicates the absorbance value of 0.2 or high corresponding to condia level which is visible to the naked eye.

indirect ELISA, was high enough to be detectable up to $\times 12,800$ dilutions (Fig. 1).

Sensitivity of PAb. Serums produced from the two mice were harvested. In titration experiments, both PAbl and PAb2 had the highest level of reactivity to Colletotrichum gloeosporioides. Absorbance readings exceeded 0.5 even at a $10^{-5}$ dilution. Sensitivity of PAb was precise enough to detect spore concentration to as low as 50 conidia/well by indirect ELISA (Fig. 2).

Determining antigen epitope to polyclonal antibody. To determine antigen, mucous conidia surface washing vs. washed conidia was coated to plate and subsequently introduced with $\mathrm{PAb} 1$ and $\mathrm{PAb} 2$, then visualized in indirect ELISA. We found interesting results that PAb1\&2 bound with supernatant fraction (mucous spore surface washing) (Fig. 3).

Specificity of PAb. The PAbs were tested against isolates of Colletotrichum gloeosporioides; absorbance values exceeded 1.0 , but no reaction was detected with other isolates, except that from three other anthracnose strains: Colletotrichum gloeosporioides (pepper strain), Glomerella cingulata (apple strain) and Colletotrichum lagenarium (Fig. 4).

Enzyme treatment on binding of polyclonal antibody. To characterize the epitope of antigen, we treated the conidial antigens with proteinase $\mathrm{K}$, pronase $\mathrm{E}$ and trypsin. The absorbance values as determined by indirect ELISA were reduced in $5 \mathrm{~min}$ by PK and PE treatments; but reduction was lesser with the use of trypsin treatment (Fig. 5 ). Treatment of cell wall lysis enzyme did not affect the OD reading (Data not shown). This result suggests that Pabl and Pab2 bind to the protein epitope, partially containing the residue of amino acid, arginine and lysine.

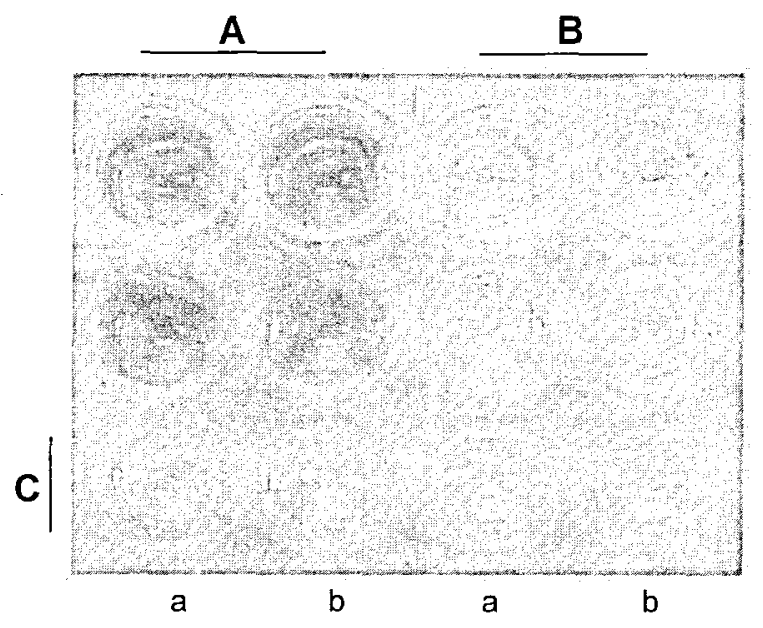

Fig. 3. Determination of antigen epitope to polyclonal antibody. A, mucous conidia surface washing; B, washed conidia; C, negative control; $a, \mathrm{PAb} 1 ; \mathrm{b}, \mathrm{Pab} 2$.

\section{Discussion}

Anthracnose of Diospyros kaki Thunb. is the most destructive disease of Persimmon. Unfortunately, before the onset of anthracnose, it is very difficult to accurately and rapidly monitor inocula on plant surface with the existing plant pathological methods. One of the approaches to achieve this goal would be for researchers to develop polyclonal antibody based-ELISA kit that can specifically detect inoculum prior to symptom development, and discriminate other epiphytic microbes on the host plants.

In order to determine appropriate antigens for their specific antigenicity, mice were immunized with conidia. The antiserum raised against conidia should be promising 

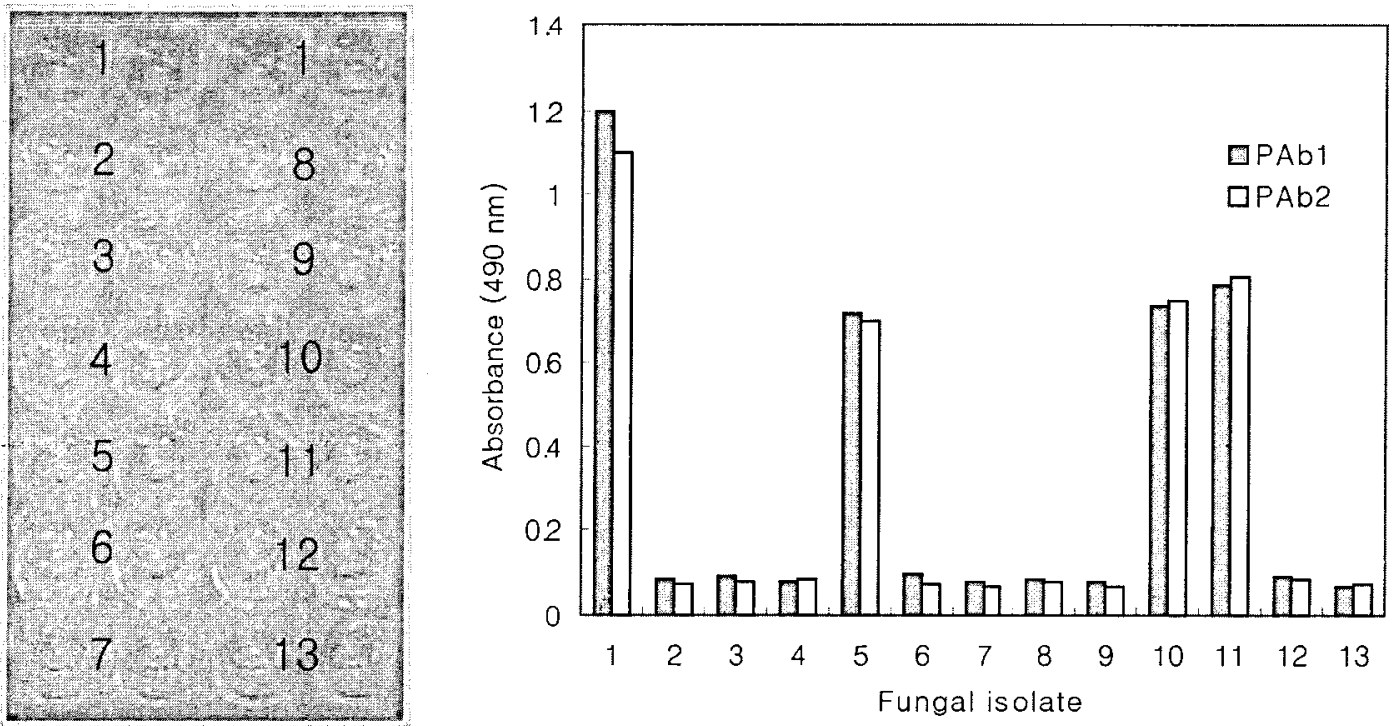

Fig. 4. Test of polyclonal antibodies PAb1 and PAb2 for cross-reaction with other pathogenic isolates. Plates were coated with fungal homogenates (50 $\mu \mathrm{l}$ per well), and antiserum was diluted 1:1,000. 1, Gloeosporium kaki; 2, Phyllactinia kakicola; 3, Cercospora kakivora; 4, Rhizoctonia solani; 5, Colletotrichum lagenarium; 6, Phytophthora capsici; 7, Fusarium oxysporum; 8, Alternaria cucumerina; 9, Cladosporium cucumerinum; 10, Glomerella cingulata (pepper); 11, Glomerella cingulata (apple); 12, Sclerotinia sclerotiorum; 13 , negative control.

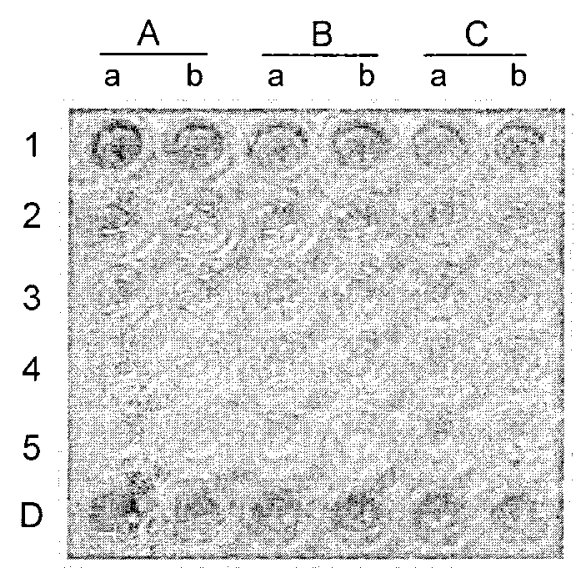

Fig. 5. Effect of enzyme treatment on binding of the PAbs 1,2 to immobilize spore of persimmon. A, Proteinase K; B, Pronase E; C, Trypsin; D, positive control; a, PAbl; b, PAb2.

for its low cross reactivity, as well as, the conidia being major sources of primary inoculums for disease cycle of anthracnose.

Both PAb1 and PAb2, developed in this study, recognized conidia of anthracnose fungi only, and discriminated others associated with sweet persimmon. This result suggests that these PAbs could be used to develop early diagnostic kits. Both Pab1 and PAb2 recognized the mucous surface washing of conidia (Fig. 3).

Generally, the threshold level of conidial concentration to penetrate and infect host tissue should be higher than $10^{6}$ spores per $\mathrm{ml}$. The sensitivity of PAb was determined by
ELISA system with coating serial dilution of conidia concentrations. Absorbance value at $490 \mathrm{~nm}$ was 0.2 or higher at 50 conidia, which is distinctive and sensitive enough for researchers to observe color reaction with the naked eye, without relying on ELISA reader, compared to 0.05 at negative control.

Specificity of our ELISA system was high enough to discriminate powdery mildew, Cercospora kakivora, from persimmon and many other fungal pathogens of horticultural crops. Unfortunately, our assay system yielded crossreaction with anthracnose fungi of watermelon, apple, and pepper (Fig. 4) as experienced by Velicheti et al. (1993).

The fact that the our assay system is cross-reactive to other anthracnose fungi at practical level may not be disadvantageous at all, because Diospyros kaki is not the host for Colletotrichum lagenarium. Taxonomy of Gloeosporium kaki was revised to C. gloeosporioides by von Arx $\mathrm{J}$. A., and G. cingulata is a telemorph of C. gloeosporioides. Still, it is likely that persimmon strains, formerly Gloeosporium kaki and other two C. gloeosporioides strains, are different from one anther despite remarkable similarity in antigenic determinant (Fig. 4). There should be some characteristics involved in such diversity other then morphology. Nevertheless, our ELISA system might also be feasible to detect anthracnose inocula for above host plants.

$\mathrm{PAb} 1$ and PAb2 antigens were characterized by various protease and cell wall lysis enzyme. When conidial suspension was treated with trypsin, proteinase $\mathrm{K}$, and 
pronase $\mathrm{E}$, it was slightly resistant to trypsin, but treatment of proteinase $\mathrm{K}$ and pronase $\mathrm{E}$ resulted in reduction of absorbance value as a function of time. This is the evidence on Pab1 and Pab2 binding to protein epitope, which partially contained residue of amino acid, arginine and lysine, even though more work needs to be done.

In conclusion, PAb1 and PAb2 proved to be very sensitive and highly specific to the target pathogen, Colletotrichum gloeosporioides, apparently discriminating other unrelated pathogens, or epiphytes. This kit fulfills the requirements for detecting inoculums before infection and onset of anthracnose, and would provide us with a more highly accurate information than that obtained with PCR method or classical identification method (Singh et al., 2000).

Moreover, PCR methods, so far reported, have relied on DNA from mycelium; hence, may be disadvantageous to detect inoculums as conidia, because current technique to isolate DNA directly from conidia has not been fully established yet.

\section{Acknowledgment}

This study was supported in part by a Research Grant From the Agricultural Research \& Promotion Center, Ministry of Agriculture and Forestry (ARPC project: 101052-02-2SB010). This work is partial fulfillment for the Degree of Bachelor of Science in Agriculture, Gyeongsang National University of senior author.

\section{References}

Clark, M. F. 1981. Immunosorbent assays in plant pathology.
Annual Rev. Phytopathology 19:83-106.

Kobayashi, T. and Katumoto, K. 1992. Taxonomic Revision and References for Imperfect Fungal Pathogens p. 590-591. (In Japanese) in Chapter 6 of the Compendium of Plant Pathogenic Fungi. 685pp. Japanese Rural Education Association. Ann Shin Printing Co. Tokyo Japan.

Kwon, J. H., Kang, S. W. and Park, C. S. 2000. Cultural characteristics of Colletotrichum gloeosporioides causing Anthracnose of persimmon. Plant disease Research 6:48-50

Lee, Y. H. and Shin, H. D. 1998. List of plant diseases in Korea. 3d edition p. 203 Korean Society of Plant Pathology World Science Co. 436pp.

Meyer, U. M., Spotts, R. A. and Dewey, F. M. 2000. Detection and quantification of Botrytis cinerea by ELISA in pear stems during cold storage. Plant Dis. 84:1099-1103.

Ryu, H. Y., Lee, Y. H., Cho, W. D., Kim, W. K., Myung, I. S. and Jin, K. S. 1993. Compendium of fruit tree diseases with colour plates. Agricultural Sciences Institute, Suwon. Gyeonggido Printing Industry Cooperative 286pp.

Singh, U., Trevors, C. M., Boer, S. H. and Janse, J. D. 2000. Fimbrial-specific monoclonal antibody-based ELISA for European potato strains of Enwinia chrysanthemi and comparison to PCR. Plant Dis. 84:443-448.

Somai, B. M. and Keinath, A. P. 2002. Development of PCRELISA for detection and differentiation of Didymella bryoniae from related phoma species. Plant Dis. 86:710-716.

Sundaram, S., Plasencia, J. and Banttari, E. E. 1991. Enzymelinked immunosorbent assay for detection of verticillium spp. Using antisera produced to $V$. dahliae from potato. Phytopathology 81:1485-1489.

Velicheti, R. K., Lamison, C., Brill, L. M. and Sinclair, J. B. 1993. Immunodetection of Phomopsis species in asymptomatic soybean plants. Plant Dis. 77:70-73. 